\title{
Evaluation of $\alpha$ - and $\beta$-Endosulfan Residues in Teas and Yerba Mate Infusions by Bar Adsorptive Microextraction and Large Volume Injection-Gas Chromatography Mass Spectrometry
}

\author{
Anaí L. dos Santos, ${ }^{a}$ Laiza C. Krause, ${ }^{b}$ Jaderson K. Schneider, ${ }^{a}$ José M. F. Nogueira ${ }^{c}$ and \\ Elina B. Caramão ${ }^{\circledR} *, a, b, d$ \\ ${ }^{a}$ Instituto de Química, Universidade Federal do Rio Grande do Sul (UFRGS), \\ 91509-900 Porto Alegre-RS, Brazil \\ ${ }^{b}$ Programa de Pós-Graduação em Biotecnologia Industrial, Universidade Tiradentes (Unit), \\ 49032-490 Aracaju-SE, Brazil \\ ${ }^{c}$ Centro de Química e Bioquímica, Faculdade de Ciências, Universidade de Lisboa, \\ 1749-016 Lisboa, Portugal \\ ${ }^{d}$ Instituto Nacional de Ciências e Tecnologia-Energia e Meio Ambiente (INCT E\&A), \\ 40170-115 Salvador-BA, Brazil
}

\begin{abstract}
Tea and yerba mate are traditional beverages prepared through the infusion of leaves of Camellia sinensis and Ilex paraguariensis, respectively. During this process, the leaching of pesticides onto the beverage, such as endosulfan, may occur. In this study, a bar adsorptive microextraction $(\mathrm{BA} \mu \mathrm{E})$ method prior to large gas chromatography mass spectrometry analysis was developed to analyze $\alpha$ - and $\beta$-endosulfan in teas and yerba mate infusions. Different sorbent coatings for $\mathrm{BA} \mu \mathrm{E}$ were compared and the hydrophilic-lipophilic balanced polymer showed the best selectivity for endosulfan isomers. The method was validated providing good recoveries (varying from $80.4 \pm 1.8$ to $108 \pm 4.9 \%$ ) and linearities $\left(r^{2}>0.99\right)$ ), limits of detection from 8.0 to $4.0 \mu \mathrm{g} \mathrm{kg}^{-1}$ and limits of quantification from 40 to $20 \mu \mathrm{g} \mathrm{kg}^{-1}$ for $\alpha$ - and $\beta$-endosulfan, respectively. The application of the method in the analysis of real samples showed all free of endosulfan at the limit of detection of the analytical method.
\end{abstract}

Keywords: bar adsorptive microextraction, pesticides, tea, yerba mate, gas chromatography

\section{Introduction}

Endosulfan is a broad-spectrum organochlorine insecticide and acaricide. Its technical grade is a mixture of the two stereoisomers, $\alpha$ - and $\beta$-endosulfan, in approximately $2: 1$ to $7: 3$ ratio, respectively. ${ }^{1}$ While most organochlorine pesticides have been banned since the 1980 's, endosulfan is one of the few which has still been used in a variety of food crops for the last sixty years. ${ }^{2,3}$ Due to its several risks to human health and the environment, the Stockholm Convention on Persistent Organic Pollutants ${ }^{4}$ has recommended the global ban on the manufacture and use of endosulfan.

Despite a large number of countries and the European Union having already banned the use of endosulfan, ${ }^{5}$

*e-mail: elina@ufrgs.br residues are still being detected in foods like tea (Camellia sinensis) ${ }^{6,7}$ due to its extensive use in China, ${ }^{3}$ the world's largest tea grower and exporter. ${ }^{8}$

In view of this, different regions have created regulations and set maximum residue levels (MRLs) for endosulfan in tea. For example, the Japan's Ministry of Health, Labour, and Welfare has established $30 \mathrm{mg} \mathrm{kg}^{-1}$ as the MRL for endosulfan (as a sum of $\alpha$ - and $\beta$-endosulfan), ${ }^{9}$ while the European Communities Regulation ${ }^{10}$ has set the same MRLs value, however it is the sum of the isomers and endosulfan sulfate, their major metabolite. ${ }^{1}$

Yerba mate (Ilex paraguariensis) is a native plant from a subtropical region of South America. Their dried leaves and twigs are used to prepare a traditional infused drink called "mate", "chimarrão" or "tererê", ${ }_{11}^{11}$ a symbol of Argentinian, Uruguayan, Paraguayan, and Southern Brazilian cultures. Until recently, these countries had been some of the world's 
largest endosulfan consumers. However, in obedience to the Stockholm Convention, the use of this pesticide has been forbidden in these countries. ${ }^{12,13}$

Over the last decade, yerba mate has been introduced to Europe, North America, and Asia. It is commercialized as a health food, and used to prepare infusion or extracts to manufacture functional foods and phytopharmaceutical preparations. ${ }^{14}$ The European Commission has established a MRL of $0.1 \mathrm{mg} \mathrm{kg}^{-1}$ for endosulfan on yerba mate leaves, ${ }^{10}$ while Japan's Ministry of Health does not have a limit specified. ${ }^{9}$

Tea and yerba mate, that can be considered "tea-like" matrix, are complex matrices for trace level analyses, due its chemical composition. ${ }^{15,16}$ Therefore, an efficient methodology for sample preparation is required prior to analysis, in which extraction is the most critical step. The extraction procedure should ensure selectivity and a large concentration factor for the target compounds. ${ }^{15}$

Recently, bar adsorptive microextraction $(\mathrm{BA} \mu \mathrm{E})$ techniques have been developed and applied on trace analysis of polar-to-nonpolar analytes in aqueous media. ${ }^{77,18}$ These techniques are based on the floating sampling technology. Also, they allow for sorbent coating selection, which results in increased selectivity on the extraction of analytes at the trace level. The main advantages of the $\mathrm{BA} \mu \mathrm{E}$ over conventional sample preparation techniques are the reduced costs associated, in comparison to other techniques, that deal with similar limits of identification and quantification, ${ }^{17}$ such as solid-phase extraction (SPE) and solid-phase microextraction (SPME).

This study aims to evaluate the performance of $\mathrm{BA} \mu \mathrm{E}$, as well as the established extraction method stir bar sorptive extraction (SBSE) for $\alpha$ - and $\beta$-endosulfan extraction from tea and yerba mate infusions. The analyses were performed by large volume injection-gas chromatography coupled to mass spectrometry operating in selected-ion monitoring acquisition mode (LVI-GC-MS(SIM)). The selectivity of different $\mathrm{BA} \mu \mathrm{E}$ sorbent coatings was compared, and the developed methodology was validated and applied in real teas and yerba mate samples.

\section{Experimental}

\section{Standard materials and samples}

High performance liquid chromatography (HPLC)-grade methanol (99.8\%) was purchased from Carlo Erba (Arese, Italy). Ultrapure water was obtained from Mili-Q system (Massachussets, USA). Analytical standard, a mixture of $\alpha$ and $\beta$-endosulfan (2:1) was purchased from Sigma-Aldrich (Steinheim, Germany). SBSE (Twister $\left.{ }^{\circledR}\right)(20 \mathrm{~mm}$ length,
$0.5 \mathrm{~mm}$ polydimethylsiloxane (PDMS) layer, $47 \mu \mathrm{L}$ ) were obtained from Gerstel (Mülheim and der Ruhr, Germany).

Five types of sorbents were tested as sorbent coatings for BA $\mathrm{EE}$ : an activated carbon (R, surface area $937 \mathrm{~m}^{2} \mathrm{~g}^{-1}$, $\mathrm{pH}$ at the point of zero charge $\left(\mathrm{pH}_{\mathrm{PZC}}\right) 6.5$, Riedel-de-Haën, Seelze, Germany), a bonded silica octadecylsilane $\left(\mathrm{C}_{18}\right.$, particle size $45 \mu \mathrm{m}$, surface area $480 \mathrm{~m}^{2} \mathrm{~g}^{-1}, \mathrm{pH}$ stability: 2-8, Supelco, Darmstadt, Germany), and 3 polymeric phases, namely, polystyrene-divinylbenzene (PS-DVB, particle size 40-120 $\mu \mathrm{m}$, surface area $1200 \mathrm{~m}^{2} \mathrm{~g}^{-1}, \mathrm{pH}$ stability: 1-13, Merck, New Jersey, USA), hydrophiliclipophilic balanced (HLB, particle size 30-60 $\mu \mathrm{m}$, surface area $810 \mathrm{~m}^{2} \mathrm{~g}^{-1}, \mathrm{pH}$ stability: 1-14, Waters, Massachusetts, USA) and, Strata $\mathrm{X}$, a modified styrene-divinylbenzene polymer (STX, particle size $85 \mu \mathrm{m}$, surface area $800 \mathrm{~m}^{2} \mathrm{~g}^{-1}$, pH stability: 1-14, Phenomenex, California, USA).

Seven tea samples (Camellia sinensis) from different origins were purchased across Lisbon and named: A (Vietnam), B (Sri Lanka), C (unknown origin), D (China), $\mathrm{E}$ (India), F (China), and $\mathrm{H}$ (Portugal). A yerba mate (Ilex paraguariensis) package (named G) was purchased in a Brazilian market.

\section{Extraction set-up}

The lab-made of the $\mathrm{BA} \mu \mathrm{E}$ devices and extraction procedure were performed according to described in a previous study. ${ }^{19}$ The BA $\mu$ Es coated with different sorbent phases and the SBSE device were evaluated in recovery studies using fortified ultrapure water $\left(1 \mu \mathrm{g} \mathrm{L} \mathrm{L}^{-1}\right.$ of endosulfan mixture). The assays were performed under standard experimental conditions: $25 \mathrm{~mL}$ of fortified ultrapure water, extraction time of $16 \mathrm{~h}$ (1000 rpm) and $\mathrm{pH}$ 5.5. After that, the devices were removed from the samples and submitted to a back-extraction procedure using methanol $(100 \mu \mathrm{L}, 30 \mathrm{~min})$ under ultrasonic treatment. After the back-extraction, the samples were subjected to LVI-GC-MS(SIM) analyses. The extraction efficiency was determined by comparing the amounts of endosulfan extracted with ones present in the solution.

The sample selected for method validation was the Portuguese tea (sample H), which represented a sample free of endosulfan. The calibration curves were made using standard addition method (SAM, 4 concentrations levels) and the performance was assessed in terms of linearity, recovery (3 concentrations levels), limit of detection (LOD), limit of quantification (LOQ) and repeatability. Infusion preparation: $1 \mathrm{~g}$ of tea or yerba mate was spiked with working standard mixture of $\alpha$ - and $\beta$-endosulfan at desired concentrations and the sample was submerged in $400 \mathrm{~mL}$ water $\left(10 \mathrm{~min}, 80^{\circ} \mathrm{C}\right)$. Afterwards, the infusions 
were filtered through filter paper and $25 \mathrm{~mL}$ of each infusion was submitted to the extraction procedure as described above for recovery studies. The extraction device used was that one most effective for recovery of endosulfan isomers.

The developed methodology was applied to quantify $\alpha$ - and $\beta$-endosulfan in teas and yerba mate infusions (samples A to G).

All the experiments were made in triplicate. Furthermore, blank assays were performed using the procedure described without spiking.

\section{Instrumental set-up}

The LVI-GC-MS analysis was performed using an Agilent 6890 Series gas chromatograph equipped with an Agilent 7683 automatic sampler coupled to an Agilent 5973N mass selective detector (Agilent Technologies, Delaware, USA). The programed temperature vaporization injector operated in the solvent-vent injection mode (vent time: $0.30 \mathrm{~min}$; flow: $50 \mathrm{~mL} \mathrm{~min} \mathrm{~m}^{-1}$; pressure: $0 \mathrm{psi}$; purge: $60 \mathrm{~mL} \mathrm{~min}^{-1}$ at $2 \mathrm{~min}$ ) with compressed air for inlet cooling. Inlet temperature was programed from $45{ }^{\circ} \mathrm{C}$ (0.35 min) to $320^{\circ} \mathrm{C}(3 \mathrm{~min})$ at a rate of $600{ }^{\circ} \mathrm{C} \mathrm{min}^{-1}$ and decreased to $200{ }^{\circ} \mathrm{C}$ at a rate of $50^{\circ} \mathrm{C} \mathrm{min}^{-1}$. Injection volume and carrier gas flow were set at $20 \mu \mathrm{L}$ and $100 \mu \mathrm{L} \mathrm{min}^{-1}$, respectively. GC analysis was performed using a capillary column Zebron ZB-5 (30 m $\times 0.25 \mathrm{~mm}$ internal diameter, $0.25 \mu \mathrm{m}, 5 \%$ diphenyl, 95\% dimethyl-polysiloxane) purchased from Phenomenex (Torrance, USA) using helium as the carrier gas at $40 \mathrm{~cm} \mathrm{~s}^{-1}$. Oven temperature was: $45^{\circ} \mathrm{C}$ (1 min) at $13{ }^{\circ} \mathrm{C} \mathrm{min}^{-1}$ until $300{ }^{\circ} \mathrm{C}$. Transfer line, ion source and quadrupole analyzer temperatures were 280,230 and $150{ }^{\circ} \mathrm{C}$, respectively. External standard methodology was used to assess the instrumental calibration. Instrument performance was evaluated in terms of linearity, LOD, LOQ and, precision.

\section{Results and Discussion}

\section{Assessment of the methodology}

The best GC-MS instrumental conditions were established for $\alpha$ - and $\beta$-endosulfan analysis. The mass spectral fragmentation pattern of the isomers was obtained in full-scan mode and specific ions (207, 241 and $339 \mathrm{Da})$ were selected to obtain high sensitivity in SIM mode. The subsequent analysis adopted the GC-MS(SIM) approach.

The limits of detection and quantification were determined by injection of diluted standards and calculated with a signal-to-noise ratio of 3 and 15, respectively. As a result, LODs (5.0 and $\left.2.5 \mu \mathrm{g} \mathrm{L}^{-1}\right)$ and LOQs (25.0 and $12.5 \mu \mathrm{g} \mathrm{L} \mathrm{L}^{-1}$ ) were obtained for $\alpha$ - and $\beta$-endosulfan, respectively. Instrumental calibration was evaluated in the range of 25.0 to 250 and 12.5 to $125 \mu \mathrm{g} \mathrm{L}^{-1}$, using 6 concentration levels, for $\alpha$ - and $\beta$-endosulfan, respectively, with determination coefficients $\left(\mathrm{r}^{2}\right)$ not less than 0.996. Instrument precision, calculated as percentage of relative standard deviation (RSD) for 5 measurements of each standard level, was lower than $10 \%$.

\section{Recovery studies}

Recovery studies were conducted in ultrapure water spiked with the pesticide. The solution was subjected to extraction procedure with $\mathrm{BA} \mu \mathrm{E}$, coated with five different sorbents, and SBSE, in order to compare the extraction ability. Figure 1 depicts the average extraction recoveries (in percentage) together with relative standard deviations (RSD, in percentage).

The $\mathrm{BA} \mu \mathrm{E}(\mathrm{R})$ was the least effective to retain endosulfan isomers. The active carbon sorbents are solid materials with large specific area and active porous in which solutes can be retained by electrostatic and/or dispersive

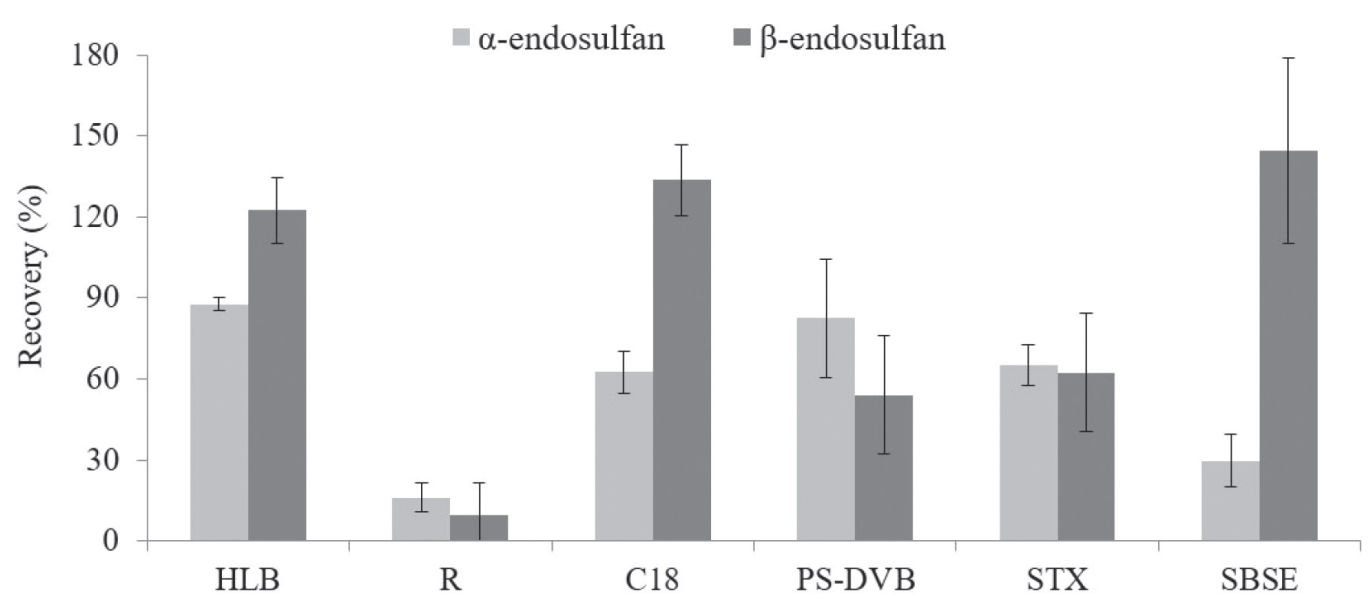

Figure 1. Comparison of the recovery yields obtained for $\alpha$ - and $\beta$-endosulfan by BA $\mu$ E using different sorbent phases and SBSE device. 
interactions. ${ }^{17}$ At $\mathrm{pH}$ 5.5, the matrix $\mathrm{pH}$ value is lower than $\mathrm{R}$ sorbent $\mathrm{pH}_{\mathrm{PZC}}$, so the surface material becomes slightly positively charged. The absence of $\mathrm{p} K_{\mathrm{a}}$ value for endosulfan indicates that ionization cannot occur in these molecules, due to the absence of acid protons or basic centers in their structure. ${ }^{20,21}$ Consequently, in that experimental condition, attractive or repulsive interactions between the sorbent $R$ and endosulfan may not occur.

SBSE was able to extract $\beta$-endosulfan; however it was less effective than the polymeric devices and $\mathrm{BA \mu E}(\mathrm{C} 18)$ to extract $\alpha$-endosulfan. The BA $\mu \mathrm{E}(\mathrm{PS}-\mathrm{DVB})$ and $\mathrm{BA} \mu \mathrm{E}(\mathrm{STX})$ were efficient to retain $\alpha$-endosulfan, but were poorly able to retain $\beta$-endosulfan, whereas $B A \mu E(H L B)$ and $\mathrm{BA} \mu \mathrm{E}(\mathrm{C} 18)$ provided the higher extraction efficiency for both isomers. These polymeric-based materials such as HBL retain solutes according to specific interaction mechanisms between the sorbents and the target compound, mainly $\pi-\pi$, dipole-dipole, hydrogen bonding and ionic interactions. The particle size and material surface area were also important characteristics involved in the process. ${ }^{17}$

$\mathrm{BA} \mu \mathrm{E}(\mathrm{HLB})$ showed the most effective recovery of the hydrophobic endosulfan isomers: $88.0 \pm 2.0$ and $122 \pm 12 \%$ for $\alpha$ and $\beta$-endosulfan, respectively. This material combined the hydrophilic and lipophilic properties with higher specific surface area and lower particle size, which allowed for better recoveries. In this way, BA $\mu \mathrm{E}$ (HLB) was chosen to validation and application steps.

\section{Validation of the $B A \mu E(H L B) / L V I-G C-M S(S I M)$ methodology}

In order to evaluate the developed extraction methodology, sample $\mathrm{H}$ was spiked with known amounts of $\alpha$ - and $\beta$-endosulfan and infusions were prepared as described in Experimental section. The extractions were performed by BA $\mu \mathrm{E}$ (HLB), under standard extraction conditions and the samples were analysed by LVI-GC-MS(SIM). The performance was assessed in terms of LOD, LOQ, linearity, recovery and repeatability. Table 1 summarizes the results.

Limits of detection and quantification were determined by injection of diluted samples and calculated with a signalto-noise ratio of 3 and 15 , respectively. The linearity was evaluated in the range of 40.0 to 400 and 20.0 to $200 \mu \mathrm{g} \mathrm{kg}^{-1}$ for $\alpha$ - and $\beta$-endosulfan, respectively. The $\mathrm{r}^{2}$ values were $>0.99$, which was remarkable considering the complexity of the matrix. The recoveries were performed at concentrations levels: 80, 160 and $240 \mu \mathrm{g} \mathrm{kg}^{-1}$ for $\alpha$-endosulfan, and 40, 80 and $120 \mu \mathrm{g} \mathrm{kg}^{-1}$ for $\beta$-endosulfan, and results ranged from $80.4 \pm 1.8$ to $108 \pm 4.9 \%$. Repeatability (percentage RSD for 5 replicate injections) was determined at concentration levels: 160 and $240 \mu \mathrm{g} \mathrm{kg}^{-1}$ for $\alpha$-endosulfan and 80 and $120 \mu \mathrm{g} \mathrm{kg}^{-1}$ for $\beta$-endosulfan, and ranged from 4.0 to $9.0 \%$.

As can be seen in Table 1, the obtained limit of quantification was $60 \mu \mathrm{g} \mathrm{kg}^{-1}$ (as a sum of $\alpha$ - and $\beta$-endosulfan), much lower than MRLs required for this particular matrix. ${ }^{9}$ The results demonstrated the potential

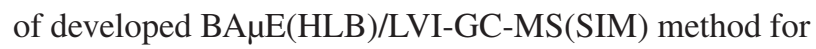
analysis endosulfan isomers in tea infusion samples at trace level.

Table 2 summarizes the comparison of the LOD, LOQ and average recovery achieved in this research with others techniques reported in the literature for endosulfan analyses.

According to the data, the proposed methodology presents recovery, LODs and LOQs in the same order of magnitude of currently sample preparation techniques, such as SPE, SPME, magnetic nanoparticles extraction (MNP), dynamic hollow fiber protected liquid phase microextraction (DHFP-LPME) and quick, easy, cheap, effective, robust and safe method (QuEChERS), even when they were combined with gas chromatography with electron capture detector (GC-ECD), two-dimensional gas chromatography $(\mathrm{GC} \times \mathrm{GC})$ and tandem mass spectrometry (MS/MS) systems. ${ }^{6,22,23,26-28}$

Furthermore, the reduced costs associated, labor intensity and time effectiveness (in spite of long extraction time), are fairly better when compared with other approaches (e.g., SPE, SPME). The developed method is an alternative to current extraction methods, with comparable LOD and LOQ, and satisfactory recovery for trace analysis of $\alpha$ and $\beta$-endosulfan in tea and yerba mate samples.

\section{Application to real matrices}

The ability of the developed BA $\mu \mathrm{E}(\mathrm{HLB}) / \mathrm{LVI}-\mathrm{GC}$ MS(SIM) methodology to determine $\alpha$ - and $\beta$-endosulfan

Table 1. Validation parameters obtained by BA $\mu \mathrm{E}(\mathrm{HLB}) / \mathrm{LVI}-\mathrm{GC}-\mathrm{MS}(\mathrm{SIM})$

\begin{tabular}{|c|c|c|c|c|c|c|c|}
\hline \multirow{2}{*}{ Compound } & \multicolumn{3}{|c|}{ Recovery / \% } & \multirow{2}{*}{$\mathrm{LOD} /\left(\mu \mathrm{g} \mathrm{kg}^{-1}\right)$} & \multirow{2}{*}{$\mathrm{LOQ} /\left(\mu \mathrm{g} \mathrm{kg}^{-1}\right)$} & \multirow{2}{*}{$\mathrm{LR} /\left(\mu \mathrm{g} \mathrm{kg}^{-1}\right)$} & \multirow{2}{*}{$\mathrm{r}^{2}$} \\
\hline & Level 1 & Level 2 & Level 3 & & & & \\
\hline$\alpha$-Endosulfan & $108 \pm 4.9$ & $80.8 \pm 2.2$ & $80.4 \pm 1.8$ & 8.0 & 40.0 & $40.0-400$ & 0.995 \\
\hline$\beta$-Endosulfan & $107 \pm 8.7$ & $84.9 \pm 10$ & $83.5 \pm 9.8$ & 4.0 & 20.0 & $20.0-200$ & 0.991 \\
\hline
\end{tabular}

LOD: limit of detection; LOQ: limit of quantification; LR: linear range; $\mathrm{r}^{2}$ : linearities. 
Table 2. Current methodologies for endosulfan analysis in tea samples

\begin{tabular}{|c|c|c|c|c|c|c|c|c|}
\hline \multirow{2}{*}{$\begin{array}{l}\text { Sample } \\
\text { preparation }\end{array}$} & \multirow{2}{*}{$\begin{array}{l}\text { Instrument } \\
\text { system }\end{array}$} & \multicolumn{3}{|c|}{$\alpha$-Endosulfan } & \multicolumn{3}{|c|}{$\beta$-Endosulfan } & \multirow[b]{2}{*}{ Reference } \\
\hline & & $\begin{array}{c}\text { LOD / } \\
\left(\mu \mathrm{g} \mathrm{kg}^{-1}\right)\end{array}$ & $\begin{array}{c}\text { LOQ / } \\
\left(\mu \mathrm{g} \mathrm{kg}^{-1}\right)\end{array}$ & Recovery / \% & $\begin{array}{c}\text { LOD / } \\
\left(\mu \mathrm{g} \mathrm{kg}^{-1}\right)\end{array}$ & $\begin{array}{c}\text { LOQ / } \\
\left(\mu \mathrm{g} \mathrm{kg}^{-1}\right)\end{array}$ & Recovery / \% & \\
\hline DHFP-LPME & GC-ECD & 20 & 50 & 7.70 & - & - & - & 22 \\
\hline SPME & GC $\times$ GC/TOF-MS & N.R. & 27 & N.R. & - & - & - & 23 \\
\hline D-SPE & GC-NCI-MS & 0.3 & 0.9 & 101 & 0.2 & 0.7 & 103 & 24 \\
\hline QuEChERS & GC-MS/MS & N.R. & 0.01 & $77.0-101$ & N.R. & 0.01 & $77.0-89$ & 25 \\
\hline QuEChERS & GC-MS & $\leq 5.0$ & $\leq 20$ & $91.0-111$ & $\leq 5.0$ & $\leq 20.0$ & $89.0-105$ & 26 \\
\hline LLE & GC-NCI-MS & 0.2 & 0.7 & $80.0-101$ & 0.1 & 0.3 & $88.0-95.0$ & 7 \\
\hline MNP & GC-MS & $18^{\mathrm{a}}$ & $60^{\mathrm{a}}$ & 73.0-109 & - & - & - & 27 \\
\hline QuEChERS & GC-MS/MS & - & - & - & 1.0 & 3.0 & $82.0-118$ & 28 \\
\hline SPE & GC-MS/MS & N.R. & 10 & $70.0-120$ & N.R. & 10 & $70.0-120$ & 6 \\
\hline $\mathrm{BA} \mu \mathrm{E}$ & GC-MS & 8.0 & 40 & $81.0-108$ & 4.0 & 20 & 83.0-107 & this study \\
\hline
\end{tabular}

LOD: limit of detection; LOQ: limit of quantification; DHFP-LPME: dynamic hollow fiber protected liquid phase microextraction; SPME: solid phase microextraction; D-SPE: dispersive solid phase extraction; QuEChERS: quick, easy, cheap, effective, robust and safe method; LLE: liquid-liquid extraction; MNP: magnetic nanoparticles extraction; SPE: solid phase extraction; BA $\mu$ E: bar adsorptive microextraction; GC-ECD: gas chromatography with electron capture detector; GC $\times$ GC/TOF-MS: two-dimensional gas chromatography with time of flight mass spectrometry; GC-NCI-MS: gas chromatography negative chemical ionization mass spectrometry; N.R.: not reported; ${ }^{\text {athe }}$ isomer was not specified.

residues in real samples was evaluated by the analyses of eight samples: four black and three green teas and, one yerba mate. In order to suppress matrix interferences, SAM was used for quantitative purposes. The samples were spiked with four working standard solutions, ranging from 40 to 400 and 20 to $200 \mu \mathrm{g} \mathrm{kg}^{-1}$ for $\alpha$ - and $\beta$-endosulfan, respectively.
The method behaved linearly, with $\mathrm{r}^{2}$ higher than 0.981 . As a result, $\alpha$ - and $\beta$-endosulfan residues were not detected in the analysed samples at the limit of detection of the analytical method. Figure 2 depicts the chromatogram profiles obtained from the eight real samples without spiking and the standard solution of the isomers.

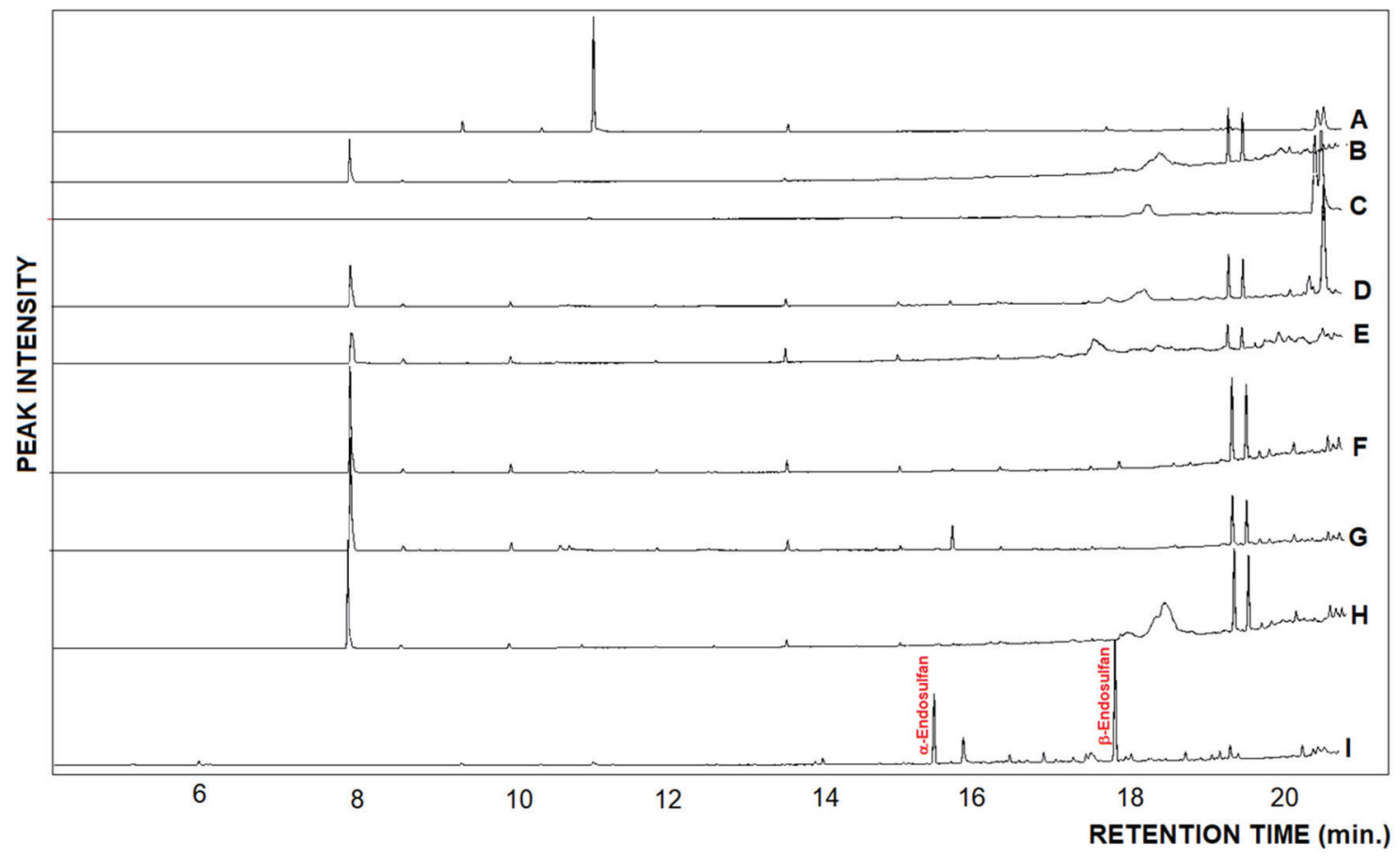

Figure 2. Chromatogram profiles of teas: A (Vietnam), B (Sri Lanka), C (unknown), D (China), E (India), F (China), H (Portugal); yerba mate G (Brazil) and, I (standard solution of $\alpha$ - and $\beta$-endosulfan) obtained by BA $\mu$ E(HLB)/LVI-GC-MS(SIM). Ions selected in SIM mode: 207, 241 and 339 Da. 


\section{Conclusions}

The present study has been developed a methodology using $\mathrm{BA} \mu \mathrm{E}(\mathrm{HLB}) / \mathrm{LVI}-\mathrm{GC}-\mathrm{MS}(\mathrm{SIM})$ for the analysis of endosulfan isomers in tea and yerba mate infusions. The sample preparation technique provided considerable selectivity for the target compounds at trace level, even in complex matrices. That allowed for limits of detection and quantification and recoveries comparable to extraction techniques which are currently applied for tea matrix. This performance allowed for to get lower than the MRLs established for this pesticide. The main advantage of the proposed methodology was the overall cost, when compared to SPE and SPME. The real samples analysed were free of endosulfan residues at the limit of detection of the analytical method.

\section{Acknowledgments}

Authors thank to CAPES and CNPq, Brazilian governmental institutions that promote scientific and technological development, for the financial support of this work.

\section{References}

1. Siddique, T.; Zahir, A. Z.; Frankenberger Jr., W. T.; J. Liq. Chromatogr. Relat. Technol. 2003, 26, 1069.

2. Barrett, K.; Jaward, F. M.; Int. J. Environ. Health Res. 2012 , 22,481 .

3. Niu, L.; Xu, C.; Zhu, S.; Liu, W.; Environ. Pollut. 2016, 219 , 315.

4. Xu, W.; Wanga, X.; Cai, Z.; Anal. Chim. Acta 2013, 790, 1.

5. Sin, D. W. M.; Wong, Y.; Accredit. Qual. Assur. 2015, $20,495$.

6. Hayward, D. G.; Wong, J. W.; Par, H. Y.; J. Agric. Food Chem. 2015, 63, 8116.

7. Zhu, P.; Miao, H.; Du, J.; Zou, J.; Zhang, G.; Zhao, Y.; Wu, Y.; J. Agric. Food Chem. 2014, 62, 7092.

8. Görür, F. K.; Keser, R.; Akçay, N.; Dizman, S.; Okumusoglu, N. T.; Food Control 2011, 22, 2065.

9. Japan's Ministry of Health, Labour, and Welfare: Notification No. 370, 1959, amendment No. 499, 2005 (update on 5 February, 2007). Available at http://www.mhlw.go.jp/english/topics/ foodsafety/positivelist060228/dl/index-1b.pdf/, accessed in August 2019.
10. European Commission: Commission Regulation (EU) No. 310/2011 of 28 March 2011 amending Annexes II and III to Regulation (EC) No 396/2005; Official Journal of the European Union, 2011. Available at https://eur-lex.europa.eu/LexUriServ/ LexUriServ.do?uri=OJ:L:2011:086:0001:0050:EN:PDF, accessed in August 2019.

11. Heck, C. I.; Demejia, E. G.; J. Food Sci. 2007, 72, 138.

12. Dores, E. F. G. C.; Spadotto, C. A.; Weber, O. L. S.; Villa, R. D.; Vecchiato, A. B.; Pinto, A. A.; J. Agric. Food Chem. 2016, 64, 3942.

13. Astoviza, M. J.; Cappelletti, N.; Bilos, C.; Migoya, M. C.; Colombo, J. C.; Chemosphere 2016, 144, 1459.

14. Anesini, C.; Turner, S.; Cogoi, L.; Filip, R.; LWT-Food Sci. Technol. 2012, 45, 299.

15. Li, X.; Zhang, Z.; Li, P.; Zhang, Q.; Zhang, W.; Ding, X.; Food Res. Int. 2013, 53, 649.

16. Pareja, L.; Niell, S.; Vryzas, Z.; González, J.; Cesio, M. V.; Mourkidou, E. P.; Heinzen, H.; Rev. Bras. Farmacogn. 2015, $25,98$.

17. Nogueira, J. M. F.; Anal. Chim. Acta 2012, 757, 1.

18. Ide, A. H.; Ahmad, S. M.; Neng, N. R.; Nogueira, J. M. F.; J. Pharm. Biomed. Anal. 2016, 129, 593.

19. Neng, N. R.; Silva, A. R.; Nogueira, J. M. F.; J. Chromatogr. A 2010, 1217, 7303.

20. Landeros, C. R.; Díaz, C. E. B.; Cháves, A. A.; Morales, G. R.; Fuel 2017, 198, 91.

21. Pilli, S. R.; Banerjee, T.; Mohanty, K.; Chem. Prod. Process Model. 2013, $8,1$.

22. Huang, S.; Huang, S.; J. Chromatogr. A 2006, 1135, 6.

23. Schurek, J.; Portolés, T.; Hajslova, J.; Riddellova, K.; Hernández, F.; Anal. Chim. Acta 2008, 611, 163.

24. Zhang, X.; Mobley, N.; Zhang, J.; Zheng, X.; Lu, L.; Ragin, O.; Smith, C. J.; J. Agric. Food Chem. 2010, 58, 11553.

25. Cajka, T.; Sandy, C.; Bachanova, V.; Drabova, L.; Kalachova, K.; Pulkrabova, J.; Hajslova, J.; Anal. Chim. Acta 2012, 743, 51.

26. Amirahmadi, M.; Shoeibi, S.; Abdollahi, M.; Rastegar, H.; Khosrokhavar, R.; Hamedani, M. P.; Iran. J. Environ. Health Sci. Eng. 2013, 10, 9.

27. Deng, X.; Guo, Q.; Chen, X.; Xue, T.; Wang, H.; Yao, P.; Food Chem. 2014, 145, 853.

28. Domínguez, G. M.; Bolaños, P. P.; González, R. R.; Frenich, A. G.; J. Sep. Sci. 2014, 37, 665.

Submitted: April 21, 2019

Published online: September 4, 2019 